American Journal of Environmental Sciences 1 (3): 187-189, 2005

ISSN 1553-345X

(c) 2005 Science Publications

\title{
Effectiveness of Ultrasound on the Destruction of $E$. coli
}

\author{
Mohammad Hadi Dehghani \\ Department of Environmental Health Engineering, School of Public Health \\ Center for Environmental Health Research, Tehran University of Medical Sciences, Tehran, Iran
}

\begin{abstract}
The aim of this study was to investigate the impact of sonication as a disinfection method for determining the effectiveness of ultrasound waves on the inactivation of $E$. coli. Ultrasound waves at a frequency of $42 \mathrm{kHz}$ were used to expose aqueous suspension of $E$. coli. Ultrasound waves display a strong influence on the rate of $E$. coli disruption in water. Inactivation occurs most at the highest sonication time. This study show that sonication in $42 \mathrm{kHz}$ is capable to some degree of inactivating $E$. coli.
\end{abstract}

Key words: $E$. coli, sonication, disinfection, ultrasound wave, frequency

\section{INTRODUCTION}

Escherichia coli or E. coli is a type of fecal coliform bacteria commonly found in the intestines of animals and humans. The presence of E. coli in water is a strong indication of recent sewage or animal waste contamination. Sewage may contain many types of disease-causing organisms. Currently, there are four recognized classes of enterovirulent $E$. coli (collectively referred to as the EEC group) that cause gastroenteritis in humans. Among these is the enterohemorrhagic (EHEC) strain designated E. coli O157:H7. E. coli is a normal inhabitant of the intestines of all animals, including humans. When aerobic culture methods are used, E. coli is the dominant species found in feces. Normally $E$. coli serves a useful function in the body by suppressing the growth of harmful bacterial species and by synthesizing appreciable amounts of vitamins. A minority of $E$. coli strains is capable of causing human illness by several different mechanisms. E. coli serotype $\mathrm{O} 157: \mathrm{H} 7$ is a rare variety of E. coli that produces large quantities of one or more related, potent toxins that cause severe damage to the lining of the intestine. These toxins [verotoxin (VT), shiga-like toxin] are closely related or identical to the toxin produced by Shigella dysenteriae ${ }^{[1,2]}$.

The presence of $E$. coli in water is a strong indication of recent sewage or animal waste contamination. Sewage may contain many types of disease-causing organisms. Water can be contaminated in a variety of ways. Main sources of E. coli are municipal sewage discharges or runoff from failing septic systems, animal feed operations, farms and faeces deposited in woodlands from warm blooded animals. In urban areas, the $E$. coli from the excrement of warm blooded animals (such as pets in a park or on the street) may be washed into creeks, rivers, streams, lakes, or groundwater during rainfalls or snow melts. The contamination in water is often highest immediately following a storm, because of the runoff. In addition, infected bathers can unknowingly contaminate water, or contamination can occur from boaters discharging wastes directly into the water. When these waters are used as sources of drinking water and the water is not treated or inadequately treated, E. coli may end up in drinking water ${ }^{[1,3]}$.

The water can be treated using chlorine, ultra-violet light, or ozone, all of which act to kill or inactivate $E$. coli. Systems using surface water sources are required to disinfect to ensure that all bacterial contamination is inactivated, such as E. coli. Systems using ground water sources are not required to disinfect, although many of them do ${ }^{[4]}$.

Several studies have shown that the efficiency of disinfection technique is dependant on the concentration of suspended solids. Because suspended solids can protect bacteria from being destroyed by disinfectants. For example, the efficiency of ultraviolet irradiation is affected by high concentrations of suspended matter.

Also, chlorine is traditionally used for disinfection. With the use of chlorine a possibility exists that byproducts may form, which are potentially toxic and carcinogenic. Due to these problems alternative disinfection techniques are being evaluated and the benefits of the use of ultrasound in the water industry are now of considerable interest ${ }^{[5,6]}$.

The one way to inactivate Ecoli is with ultrasound. When liquids are exposed to these vibrations, both physical and chemical changes occur as a result of a physical phenomenon, known as cavitation. Cavitation is the formation, expansion and implosion of microscopic gas bubbles in liquid as the molecules in the liquid absorb ultrasound energy. Compression and

Corresponding Author: Mohammad Hadi Dehghani, Department of Environmental Health Engineering, School of Public Health, Center for Environmental Health Research, Tehran University of Medical Sciences, Tehran, Iran 
rarefaction waves rapidly move through the liquid media. If the waves are sufficiently intense they will break the attractive forces in the existing molecules and create gas bubbles. As additional ultrasound energy enters the liquid, the gas bubbles grow until they reach a critical size. On reaching a critical size, the gas bubbles implode or collapse. The energy that exists within the cavity and in the immediate vicinity of the gas bubbles just before collapse causes both physical and chemical effects in the liquid. Physical effects result when cavitation is intense enough to rupture cell membranes, free particulates from solid surfaces and destroy particles and organisms through particulate collisions or by forcing them apart ${ }^{[6-8]}$.

In this study, the major objective was determining the effectiveness of ultrasound waves on the destruction of E. coli in water.

\section{MATERIALS AND METHODS}

Ultrasound Batch Reactor: Ultrasound was applied to samples using a Laboratory cleaning bath with the following characteristics:

$\begin{array}{lll}\text { Input: } & 220-230 \mathrm{~V} & 155 \mathrm{~W} \\ \text { Output: } & 70 \mathrm{~W} & 42 \mathrm{kHz}\end{array}$

Experiments: Microbiological experiments involved sonicating of $E$. coli and observing the effects of ultrasound upon its growth. Before sonication, the concentration of $E$. coli in water was adjusted to as high as 1600 (MPN $100 \mathrm{~mL}^{-1}$ ). This sample was added to the batch reactor in which sonication could be performed. For micro-organisms destruction investigation in ultrasound bath, small volumes (200, $400,600 \mathrm{~mL}$ ) of water have been used. All components in laboratory placed in an autoclave for disinfection before each test. The effect of sonicating different volumes of water was measured for the same time intervals. The samples were sonicated in periods of 1 , 15, 30, 45, 60, 75 and $90 \mathrm{~min}$. For each trial namely, each sample was exposed to all of the durations.

The standard test for $E$. coli carried out by the multiple - tube fermentation technique in research. In this test, results of the examination of replicate tube and dilutions are reported in terms of the Most Probable Number (MPN) of organisms present. The precision of each test depends on the number of tubes used. When drinking water is analyzed to determine, use the fermentation technique with 10 replicate tubes each containing $10 \mathrm{~mL}, 5$ replicate tubes each containing 20 $\mathrm{mL}$, or a single bottle containing a $100 \mathrm{~mL}$ sample portion. E. coli test (using EC medium) is applicable to investigations of drinking water, stream pollution, raw water sources, wastewater treatment systems and general water quality monitor. Submit all presumptive fermentation tubes showing any amount of gas, growth, or acidity within $48 \mathrm{~h}$ of incubation to the $E$. coli test.
Incubate inoculated EC broth tubes in a water bath a $44.5 \pm 0.2^{\circ} \mathrm{C}$ for $24 \pm 2 \mathrm{~h}$. Place all EC tubes in water bath within $30 \mathrm{~min}$ after inoculation. Maintain a sufficient water depth in water bath incubator to immerse tubes to upper level of the medium. Gas production with growth in an EC broth culture within $24 \pm 2 \mathrm{~h}$ or less is considered a positive $E$. coli reaction. Failure to produce gas constitutes a negative reaction. If multiple tubes are used, calculate MPN from the number of positive EC broth tubes as described in standard methods book ${ }^{[9]}$.

\section{RESULTS AND DISCUSSION}

The biocidal effects of ultrasound are showed in Table 1. As it is considered by $1,15,30,45,60,75$ and $90 \mathrm{~min}$ of sonication about $0.00,78.30,87.00,98.50$, $99.60,99.70$ and $99.80 \%$ of the E. coli present are destroyed respectively. Besides, the results show that increasing the sonication time has a significant effect on bacterial kill. The results in Table 1 indicate that considerable levels all in activation can be expected at higher periods. Also, analyses showing that there was no significant difference between mean of different volumes.

Table 1: The Effect of Ultrasound on Removal of E. coli

\begin{tabular}{lcccc}
\hline & \multicolumn{2}{l}{ Removal efficiency } & & \\
Ultrasound & ---1 & & \\
time (min) & $200 \mathrm{~mL}$ & $400 \mathrm{~mL}$ & $600 \mathrm{~mL}$ & \multicolumn{1}{l}{$\begin{array}{l}\text { Average } \\
(\%)\end{array}$} \\
\hline 1 & 0.00 & 0.00 & 0.00 & 0.00 \\
15 & 79.50 & 79.50 & 76.00 & 78.30 \\
30 & 90.00 & 86.00 & 85.00 & 87.00 \\
45 & 99.00 & 98.50 & 98.00 & 98.50 \\
60 & 99.70 & 99.50 & 99.50 & 99.60 \\
75 & 99.80 & 99.70 & 99.50 & 99.70 \\
90 & 99.90 & 99.90 & 99.50 & 99.80 \\
\hline
\end{tabular}

\section{CONCLUSION}

This study indicates that ultrasound waves for water disinfection are suitable. Because ultrasound reduces the amount of chlorine required for disinfection. Also, leads to greater efficiency in destruction of bacterial cells. Ultrasound leads to the formation of dead bacterial cells. These preliminary experiments indicate that ultrasonic in the low-kHz frequency range has some efficacy in inactivating some bacterial agents that may present in water. Also, experiments show that it is possible to decrease the number of $E$. coli present in the water and that the process depends on sonication time, frequency and intensity of the ultrasound waves.

\section{ACKNOWLEDGMENT}

I would like to tank Mrs. R. Sheikhi for cooperation in Tehran University of Medical Sciences for this research. 


\section{REFERENCES}

1. seniorhealth.about.com/library/prevention

2. www.tjclarkminerals.com/bacterial_diseases/

3. www.ccme.ca/sourcetotap/

4. seniorhealth.about.com/library/prevention

5. Joyce, E. et al., 2003. The development and evaluation of electrolysis in conjunction with power ultrasound for the disinfection of bacterial suspensions. Ultrasonic Sonochemis., 10: 231-234.

6. Mahvi, A.H., M.H. Dehghani and F. Vaezi, 2005. Ultrasonic technology effectiveness in total coliforms disinfection of water. J. Appl. Sci., 5: 856-858.
7. Hua, I. and M.R. Hoffmann, 1997. Optimization of ultrasonic irradiation as advanced oxidation technology. Environ. Sci . Technol., 31: 22372243.

8. Neppiras , E.A., 1980. Acoustic Cavitation. Phys. Rep., 61: 159-251.

9. Eaton A.D., et al., 1998. Standard methods for the examination of water and wastewater. American Public Health Association, AWWA,Water Environment Federation, Washington, DC. 